\title{
Introduction: Experiencing Work in a Global Context
}

\section{Carla Dahl-Jørgensen with Nigel Rapport}

Work is not a narrow specialism. A workplace might be known as the site at which human capacities are applied for the purpose of addressing human needs (material and other). To work, one might conclude, is to be human. In his introduction to existentialism as a humanist accounting, Jean-Paul Sartre's understanding is inclusive:

[Man's] historical situations are variable (...). But what never vary are the necessities of being in the world, of having to labour and to die there. These limitations are [at once] [o]bjective, because we meet with them everywhere and they are everywhere recognizable: and subjective because they are lived [emphasis in original] and are nothing if man does not live them - if, that is to say, he does not freely determine himself and his existence in relation to them. And, diverse though man's purposes may be, at least none of them is wholly foreign to me, since every human purpose presents itself as an attempt either to surpass these limitations, or to widen them, or else to deny or to accommodate oneself to them. (1997: 45-46)

Our identity as human beings is tied to work: we are who we are through the work of living.

Acknowledgement of such insights has influenced research on working life over the last century. Much emphasis is placed on the importance of having a workplace in order for an individual to secure his or her personal identities. The advent and growth of industrialism contributed largely to this perspective. Prior to the New Economy debate and 'flexible capitalism' (Sennett 1998), workplaces under the industrial epoch were portrayed as stable and dependable spaces: a physical arena for emotional and professional growth, and a place for personal identification. The workplace was a setting where regularly patterned doings occurred, where activities performed were routine and where members partook in a clear division of labour, with rights and duties. Many ethnographic studies described workplaces as arenas where workers found meaning through the repetition of customary interactions, and commonality in styles of dressing and talking, as well as sharing in similar myths and stories (Garsten 1994; Salzer-Mörling 1998). As with 'home', workplaces have been seen as giving 'structure to time' as well as embodying 'a capacity for memory and anticipation': as such they could be understood as 'communities in microcosm', where issues of morality and values were constantly evaluated and contested (Rapport and Dawson 1998: 7).

The perspective of viewing workplace as a 'community' or a 'home' in an anthropological sense has also been pointed out by Aguilera (1996: 737), who claimed that in a workplace we could apply a similar anthropological model of social organisation as that of a village in that elements such as 'space, time, personnel, and principles of recruitment, interpersonal network formation and group maintenance' were similar although the ethnographic details may be very different. The same life-cycle of a community, in other words, could be applied to a workplace and as such they were important arenas for the creation of a sense of belonging and identification. In this manner, workplace 
became an important analytic construct and a classification of identity. Work and workplaces came to be understood as important aspects of who we were and who we wanted to become.

However, much of this argumentation is based on a model and an analytical perspective that deems a workplace to be fixed in time and space (Wallman 1979). Over the last three decades or so both academic and popular literature has challenged this notion of a stable and predictable workplace. On the contrary: there is no other arena in our lives that is now as volatile and changing as the world of work. Recent news relating to recession and economic collapse exemplifies the extent to which the once 'stable' world of work is becoming a fiction. The world of work can instead be conceptualised as one of movements, fluidity and expansion. As examples, two types of movements will form the basis of our illustration.

\section{Movement of People, Workers and Companies}

Companies and workers are relocating themselves geographically and structurally in this new era: the 'New International Division of Labour' (NIDL). Companies always seem now to be in the process of restructuring and reorganising. These processes can take the form of external changes such as off-shoring and out-sourcing, but also as the result of internal changes in which divisions or units are 'merged' together or units are downsized, or taken off the company's chart all together. Employees are also on the move, the number of transnational workers is on the increase and 'body-shopping' has become a new means of relocating labour. The increasing flow of international labour migrants crossing spatial and emotional borders is contributing to 'heterogeneity' in the workplace. Over the last decades much has been written about globally dispersed groups (GDG) where co-workers have to work with each other across temporal and spatial barriers, thus posing new challenges to concepts such as knowledge, cooperation, understanding, trust and identity (Baba 2003). The creation of a sense of 'community', in the traditional anthropological notion, can be more challenging, with differences in values, ideas and work practices separating more than uniting workers. In these cases, ethnic or national differentiation becomes one factor among many that creates a challenge for defining the workplace as a place of commonality or communion. The migrant labourers who enter and leave workplaces may indeed contribute to such spaces becoming 'non-places' (Auge 1995). With the deconstruction of traditional concepts such as culture and community over recent decades (Amit and Rapport 2002), it is important that we revisit how work is experienced in this globalized context, in particular in the light of the fundamental changes that have taken place at workplace level. The articles of Lamvik, Larsen and Rapport in this Special Issue are good examples of these types of flows and fluidity.

\section{Movement of Management Models, Concepts and Ideas}

Another form of movement is related to management tools in order to increase productivity. These models are ethnocentric in their origin in that they are usually developed in specific national and cultural contexts, but are commercialized as universal models that could be applied globally. Workers are evaluated with these 'universal' tools, undermining their individuality and the 'cultural' specificity of which they are a part. Martin (2000) has conceptualized a consequence of these processes with the term 'flexible survivor'. Her argument is based on how our perception of an 'ideal worker' has changed, with a movement away from a former industrial, stable and 'disciplined worker' towards a post-modern type, an 'adapting and flexible worker'. Martin's argument is that workers who are capable of constantly shifting both emotionally and cognitively, and across temporal and spatial barriers, are seen today 
as most valuable assets to companies. Even the 'flexibility' of the workplace cheat, the trickster or criminal who positions himself beyond the ethos of company loyalty and fealty (Mars 1994), can be seen to possess qualities of independence and lateral thinking that become attractive to co-opt. The identity of workers, it is said, is no longer primarily tied to a collectivity, be it at enterprise or co-workers' level. Their identity is on the move in different and at times contradictory directions. The articles of Damman, Knox et al. and Rapport are examples of these types of flows in this Special Issue.

\section{The Meaning of Identity at Workplaces}

For employees these types of fluidity mean that a workplace is no longer a space where long-term relationships need be the norm. The concern with the creation of 'non-places' has been debated in several authors' work, among them Beck (1992) and Bauman (1998, 2001). They have examined the challenges facing modern individuals who seek to build 'secure personal identities' in the face of flexibility and contingency at work and in a world which has become more globalized and impersonal. Habermas (1987) has pointed out that the global economy may, in a way, be undermining the building of secure identities because of the lack of 'consistency' in an individual's life-history and role identities. Issues of identity and identity construction are therefore a hallmark of these studies. How are we to understand identity at a workplace when work and workplaces are in themselves shifting, blurred and in a state of flux? In such cases we can regard the organizations and the employees alike as 'migrants': they are both in a constant state of movement. The effect of a workplace on a worker's identity, then, is problematic and not clearly defined - if not defined as dynamic and changing. What are the anchors for workers' identity when the meaning of workplace is changing and blurred?
Schwartz (1975) has made the argument that in a world of movement, individuals increasingly use time rather than space as a means to anchor identities and also to bond to others and express their membership of groups. But in the case of the volatile world of companies and working life, the aspect of time has changed too. The time that colleagues and coworkers spend together is short and variable. And yet, when companies merge, or divisions are centralized or decentralized, the history of identity is still one of the means employed to affect a bonded membership and to express longevity. Even though a division or a company as a whole prior to a merging would encompass internal differences, once the merger has taken place an historical similarity would be articulated in the hope of achieving a sense of belonging and uniqueness that differentiates the merged from others, eschewing the failure that is seen to accompany 'cultural differences' among workplace members. In this respect, identities continue to be tied to time and to location alike. So, are these new kinds of identity and new kinds of difference? Given the traditional conception of an individual worker as a member of fixed and separated workplaces which possess their own 'cultures', how are we to understand identity formation today? What is the identity of the worker in a situation of globalized work-life? How are we to understand the relationships between movement and identity in the world of work?

\section{Case-studies of Contemporary Workplaces}

The five articles that follow this introduction and that comprise this Special Issue of $A n$ thropology in Action present us with differing and shifting notions of work and workplaces, including how they are experienced at a subjective level. Here are case-studies concerning empirical examples of movement and flux in working life. They offer an anthropological 
response to the question of how these factors influence the way work is experienced in the everyday life of workers.

The articles have a specificity to them as befits five distinct ethnographies. At the same time their overlapping themes present a coherent argumentational narrative.

We begin with Lotta Björklund Larsen's, 'Cleaning (in) the Swedish Black Market'. In the article, Larsen explores how a group of Swedish middle-class people justify their consumption of black market work, mainly in the form of housemaids recruited from Eastern European countries to do cleaning at their homes. Their access to cheap labour to do tedious and routine housework at the same time as these middle-class women juggle life-work balances of their own provides the ethnographic tension here. The article points out the dilemmas surrounding definitions of 'formal' and 'informal' work, and 'private' and 'public' work-spheres. The dilemmas are exacerbated by the blurring of a home/work boundary as work organizations increasingly infringe upon the sphere of the home, exemplified here by the provision of mobile phones, subsidized or free home-PCs and intranet connections whereby the workplace can keep in increasingly close contact with workers at home in their private lives.

The theme of home/work boundaries is taken up in the article that follows by Gunnar M. Lamvik, 'The Filipino Seafarer: A Life between Sacrifice and Shopping'. In the article, Lamvik focuses on the case of Filipino seamen working for Norwegian vessels and the question of how they cope with being away from their families over a long period of time. These labour migrants are confined to their workplaces and in a very monotonous working environment. At the same time their workplace is itself on the move, potentially covering most corners of the world. There is a commoditization of the work identities of these global migrants as they are moved hither and thither according to the needs of companies and con- sumers. Contrastively, however, a meaningfulness of work is assured which allows the Filipino seafarers to manage the monotony, the feeling of a closed institution and the sense of being pawns on a maritime chess-board. This meaningfulness is provided by emotional ties to a home whose distance and discreteness maintains the distinction and the strength of conceptualisations of locale and family in the Philippines.

Commoditization is a prominent theme in the article by Hannah Knox, Damian O'Doherty, Theo Vurdubakis and Chris Westrup, 'Enacting the Global in the Age of Enterprise Resource Planning'. The article focuses on the changes to work experience caused by the introduction of a technological system called Enterprise Resource Planning (ERP) and its widespread use in large U.K. corporations. ERP systems claim to provide a means of transforming businesses into more efficient entities through better data-gathering, informationgeneration, and the integration of previously disparate sectors. Intended to increase managers' understanding of organizational processes necessary for global competitiveness, the new technology had far-reaching implications for the worker's experiences of work. In particular, the article focuses upon how ERP systems reorganized regimes of knowledge in institutional contexts. The new technique and discourse entailed workers feeling that their local and collective knowledge risked being reduced to abstracted and dislocated forms of technical expertise, and in the process commoditized. As a response to the danger that their jobs might be outsourced to cheaper contractors, workers seek novel ways of decommodifying their workplace roles: they entangle themselves in organizational processes in ways which challenge the distinct categories of 'business' and the 'technologies' deployed by managers to improve competitiveness.

The theme of appropriating new technology to global business plans continues in the article by Sigrid Damman, "“Where is your 
'F'?": Psychological Testing, Communication, and Identity Formation in a Multinational Corporation'. Damman focuses on a standardized psychological, personality-trait test adopted by a multinational automobile company. The test was applied to employees and used, too, as an instrument of self-development. Psychological inventories figured prominently in internal discourse: in the eyes of the management, the tests were highly useful in facilitating communication and providing common ground for self-appraisement. The article discusses the discourse and practice surrounding the test as a form of audit that was both individualizing and totalizing of employees. Individual workers were quick to assert themselves through the categories of the tests, but at the same time the room for diverse, independent articulations of identity at work seemed to diminish. The issue is not one of mere control, however: the discourse and practice of testing went beyond the management's intentions. Rather, the discourse of the test shifted interactions in the company onto an abstract level whose reference points and traits took attention away from aspects of local socio-cultural context.

The final article, by Nigel Rapport, "“Tensile Nationality": National Identity as an Everyday Way of Being in a Scottish Hospital', also concerns the theme of multiple and competing discourses at work, their control, and their ambiguous relation to the aim of the business at hand. The setting is a major Scottish teaching hospital in the wake of the inauguration of a new Scottish Parliament: the major constitutional change in British law for 300 years. In this context, how relevant is Scottish nationality as a discourse of identity in the workplace? Who deploys the discourse? What does Scottishness mean, for whom and when? The political change makes Scottishness a prominent aspect of public debate. At the same time, Constance Hospital operates in a global 'marketplace' of skills and employees. Furthermore, it is professionally intent on a universal and generalizing ethos of taking care of the human body irrespective of proximal identifications and identifiers such as nationality - a particularizing and relativizing conception of difference. The article therefore explores the tense situation between contrastive discourses at work - how the workplace is home to features of speech and behaviour that contradict - and how nationality is itself 'tensile'. Nationality is a part-identity strategically deployed by individual workers - management, doctors, porters - for objectives that may be both in harmony and in disharmony with the logic of the work situation.

\section{The Meaning of Work}

Work and workplace link together the five articles even while they manifest different forms of movement, fluidity and work identity. Work and workplace look outward, too, linking to an applied anthropology more generally. Since to be human is to work, the five distinct ethnographies may be construed as at the same time narratives of a universal human enterprise.

Insofar as globalization delivers an increasingly integrated context or market to the environment of human work, moreover, here is an opportunity to give an account of the human condition that is especially precise. To be human is to labour at self-provision: and human labours are increasingly interconnected across the globe. The opportunity is to apply anthropology both descriptively and prescriptively. What is the global workplace like? What should it be like? These are the questions that we try to address in this Special Issue and which offer themselves as the focus of future empirical research on working life.

Carla Dahl-Jørgensen is a professor at the Norwegian University of Science and Technology (NTNU) in Trondheim, Norway in the Department of Social Anthropology, Faculty of Social Sciences and Technology Management. Professor Dahl-Jørgensen has many years of experience con- 
ducting contract research for private and public companies as well as basic research in the field of organizational anthropology, focusing mainly on topics related to health and working environment, internationalization and globalization of working life. E-mail: carla.dahl-jorgensen@svt.ntnu.no

Nigel Rapport is Professor of Anthropological and Philosophical Studies at the University of St Andrews, where he directs the Centre for Cosmopolitan Studies. He has also held the Canada Research Chair in Globalization, Citizenship and Justice at Concordia University of Montreal. His recent publications include: Of Orderlies and Men: Hospital Porters Achieving Wellness at Work (Carolina Academic Press, 2008) and, as editor, Human Nature as Capacity: Transcending Discourse and Classification (Berghahn, 2010). E-mail: rapport@st-andrews.ac.uk

\section{References}

Aguilera, F. E. (1996), ‘Is Anthropology Good for the Company?', American Anthropologist 98: 735-742.

Amit, V. and Rapport, N. (2002), The Trouble with Community: Anthropological Reflections on Movement, Identity and Collectivity (London: Pluto).

Auge, M. (1995), Non-places (London: Verso).
Baba, M. (2003), 'Working Knowledge Goes Global: Knowledge Sharing and Performance in a Globally Distributed Team', Anthropology of Work Review 24, no. 1-2: 19-29.

Bauman, Z. (1998), Work, Consumerism and the New Poor (Buckingham: Open University Press).

(2001), The Individualized Society (Cambridge: Polity Press).

Beck, U. (1992), Risk Society (London: Sage).

Garsten, C. (1994), Apple World: Core and Periphery in a Transnational Organizational Culture (Stockholm: University of Stockholm Studies in Social Anthropology).

Habermas, J. (1987), Lifeworld and System: A Critique of Functionalist Reason, trans. T. McCarthy (Boston: Beacon Press).

Mars, L. (1994), Cheats at Work: An Anthropology of Workplace Crime (London: Gower).

Martin, E. (2000), 'Flexible Survivors', Cultural Values 4, no. 4: 512-517.

Rapport, N. and Dawson, A. (ed.) (1998), Migrants of Identity: Perceptions of Home in a World of Movement (Oxford: Berg).

Salzer-Mörling, M. (1998), Företag som kulturella uttryck (Bjärred: Academia Adacta AB).

Sartre, J-P. (1997), Existentialism and Humanism (London: Methuen).

Schwartz, T. (1975), 'Cultural Totemism', in Ethnic Identity, (ed.) G. de Vos and L. Romanucci-Ross (Palo Alto: Mayfield), 106-131.

Sennett, R. (1998), The Corrosion of Character (New York: Norton).

Wallman, S. (ed.) (1979), Social Anthropology of Work (London: Academic). 